\title{
Archaic Vertebrates and Evolutionary Principles
}

\author{
By Prof. J. Graham Kerr, F.R.S., M.P.
}

$\mathrm{R}^{\mathrm{B}}$ ECENT attendance at the discussions of the Institut International d'Embryologie and of the British Association (Section D) has impressed on me the desirability of offering-more especially to the younger generation of researchers in zoological science-a short statement of personal experience emphasizing certain general considerations, which are in my opinion useful as affording guidance along profitable lines of investigation and at the same time warning against dangerous pitfalls. I have been, in my time, responsible for a considerable number of new facts and theories relating, on one hand, to the evolutionary history of vertebrates and on the other to the general theory of evolution. I will not burden this note with bibliographical details, but refer anyone interested to my text-books on "Vertebrate Embryology" (Macmillan, 1919) and "Evolution". (Macmillan, 1926).

I may say that in my research work I have owed much to the foundations on which I was able to build-a sound training in mathematics and physics, experience of fossil collecting among the carboniferous rocks of central Scotland, and a quite unusual training in field natural history when living among the primitive Natokoi Indians of the Gran Chaco. Indications of my early interest in field natural history will be found in my various communications printed in the Ibis during the nineties of last century. I allude to this preliminary training, for it may perhaps be taken as explaining, at least in part, my somewhat unfashionable attitude towards the branches of science I have mentioned-an attitude sometimes disrespectful towards the mathematical treatment of complicated biological phenomena which have not been subjected to the prelimisary analysis into simple components essential to make them amenable to mathematical treatment, a somewhat critical attitude towards pronouncements of palæontologists based upon the inadequate foundations provided by a study of skeletal structures in ignorance of 'soft parts', and finally, an attitude of what may have seemed over-emphasis of the need in all evolutionary speculation of paying due regard to each one of the three factors: (1) structure (which alone provides actual records of evolutionary history), (2) function and (3) natural environment.

The Cambridge school of zoology, in which I received my later training, was then at an important stage of its evolution, the old school of natural history having sprouted out into a luxuriant new growth of laboratory activity under the stimulus of Balfour and Foster. Regrettably, but unavoidably, the two great branches of laboratory activity diverged as they grew : that of physiology on one hand, with Foster, Gaskell, Langley, Sherrington and the rest; and that of morphology on the other, with Balfour and his successor Sedgwick and a galaxy of colleagues of the highest distinction. The splendid zoological laboratory of to-day-an imposing memorial to the tenure of office of Prof. Stanley Gardiner-represents what, in its early days, was called, as it actually was, the morphological laboratory.

The remarkable Tripos course in zoology in those days, in addition to providing a vast amount of knowledge regarding the comparative anatomy and embryology of the main groups of the animal kingdom, exercised naturally a strong directive influence on those who passed through it. In my own case, this directive influence was affected by the recognition of two important weaknesses in the school of morphology : (1) the tendency to concentrate attention on preserved specimens, to the neglect of physiological and environmental conditioning factors, and (2) the fact that the body of observations out of which the edifice of morphological theory had been built had been gathered not from such animals as from their admittedly archaic character might be expected to yield reliable information regarding earlier evolutionary stages, but from such as happened to be easily accessible to the investigator. From this latter consideration came the determination to concentrate my lifework in research upon archaic animals in spite of the technical obstacles in the way. As my immediate interest lay in the problem of the evolution of land vertebrates or tetrapods, it was to this problem that I proceeded to devote my attention.

Of the various types of tetrapod actually surviv. ing at the present day, and therefore available for morphological study apart from mere osteology, the most archaic seemed undoubtedly to be the urodele amphibian. Of the evolutionary stages antecedent to the tetrapods or land vertebrates, on the other hand, the most archaic surviving representatives seemed undoubtedly to be the sharks, the crossopterygian ganoids, and the lungfish. The lampreys and hagfish I left on one side as liable to mislead owing to their adaptation to 
abnormal semi-parasitic habits. As regards my own research work, I determined to concentrate upon the crossopterygians and lungfish, not because I regarded them as more primitive than the selachians, but simply because our ignorance of them-particularly of their ontogeny-was more profound. The programme which I set myself, was the investigation of the three genera Polypterus, Lepidosiren and Protopterus-the embryology of which in particular was then entirely unknownin order to see to what extent they supported or contradicted the accepted canons of vertebrate morphology. I need not refer here to the carrying out of that programme or to the tragic loss to science which it involved in the premature death of that splendid naturalist John Samuel Budgett, who had taken over the Polypterus part of the programme.

The study of these archaic vertebrates proved a fascinating task as it provided solutions to many puzzling problems of vertebrate morphology. To take, for example, one organ system alone-the blood system :

Why does the headward end of the embryonic heart in the tetrapod assume that spiral twist which results in the common pulmonary artery of the adult amniote having a diagonal position, running forwards from right to left, across the root of the systemic aorta?

What is the explanation of the reduction of the fifth aortic arch in the Amniota?

Why did the main stream of blood from the hinder parts of the body in the Amniota come to be carried forward by a new vessel, the posterior vena cava, in place of the original posterior cardinal veins?

Such are examples of morphological puzzles which found their solution in the developmental phenomena of Lepidosiren.

Incidentally, these investigations convinced me that real progress in the advancement of evolutionary theory is to be made through the careful investigation of particular organ systems rather than by speculation regarding the ancestral origin of particular taxonomic groups. They have also provided useful warnings as to pitfalls in the way of the morphological investigator, the nonrecognition of which has frequently helped to inflict undeserved discredit on morphological science as a whole.

One of these is, strangely, forgetfulness of the elementary fact that all scientific theories are simply working hypotheses, fitting the knowledge of the moment, to be discarded or modified in immediate response to the requirements of new knowledge. The neglect of this principle has made itself conspicuous again and again. An excellent example is concerned with the mode of development of nerve fibres in the Vertebrata. The view I had been taught was that the nerve fibre, already fibrillated, grew out from the central nervous system and joined up secondarily with its endorgan, muscle-fibre or what not. Investigation of embryos of the large-celled Lepidosiren demonstrated that this was not the case, and that the appearances which at first sight appeared to support the accepted idea were deceptive. As it is clearly against all probability that the method of nerve development in vertebrates is not fundamentally the same throughout, it might have been expected that the alternative conclusions would have been obvious to all-either that the accepted theory was wrong, or that the observations that contradicted it were erroneous. It might have been anticipated that neurologists would have hastened to check the observations for themselves. As a matter of fact, during the twenty years or so before the preparations succumbed to the wear and tear of student demonstrations, only one single neurologist made his appearance to do so-Elliot Smith. He duly satisfied himself as to the accuracy of the observations on the motor nerve trunks of Lepidosiren and was good enough to check the general principle involved by extending them to a sensory trunk, the olfactory nerve.

While this experience with the nerve trunks of Lepidosiren exemplified well the sterilizing influence of dogma in restraining the recognition of awkward new facts, the same investigation of nerve development soon directed attention to another type of pitfall, namely, the tendency to place too implicit reliance upon one particular technique. This was provided by Harrison's basic experiment in which he showed embryonic nerve rudiments growing freely through a culture medium. The careful study of sections of embryos of Lepido. siren showed no reason to doubt the accuracy of Harrison's results so far as mere observation went, but on the other hand did show that in the actual body of the embryo the nerve trunk, instead of terminating in a free end, was already in continuity, as a simple protoplasmic bridge, with its end-organ, in this case a muscle cell, at an extremely early stage in development when the myotome had not yet begun to recede from the spinal cord ; and that accordingly reliance upon the experimental method without applying the check of different technique was apt to lead to erroneous conclusions.

This need of checking by the use of different technical methods, frequently impressed itself during the study of sections of embryos, when it was found necessary to check the evidence of paraffin sections by celloidin or conversely.

Still another and a peculiarly prevalent source of error lies in the tendency to base broad evolu. tionary generalizations upon the inadequate base 
provided by the knowledge of only a single organsystem. This is illustrated in particularly flagrant manner by conclusions based on knowledge of the skeletal system. The study of histogenesis in Lepidosiren was instructive in emphasizing the curiously vague way in which skeletal stiffening gradually spreads through the embryonic con. nective tissue-in striking contrast with the welldefined units which go to build up, say, the muscular or renal system. It is well also to recall in this connexion the readiness with which skeletal tissue, such as bone, develops secondarily in the living body in response to merely mechanical factors, as is well known to surgeons in the case of the human being. It is indicated that the greatest caution must be exercised in drawing phylogenetic conclusions from skeletal facts.

In the critical frame of mind induced by such considerations, it is astonishing to note the frequency with which palæontologists have allowed themselves to base the most far-reaching evolutionary conclusions upon a basis of purely osteological fact. The suggestion that the resemblances in general form of the skull and in the dentition between a Tasmanian wolf and a member of the Canidæ indicate genetic affinity would be recognized as absurd ; these striking resemblances are recognized as indicative simply of convergent adaptation to similar modes of life. Yet similar resemblances in skull structure between certain mammals and certain extinct reptiles have been taken as indicating the evolutionary origin of the group Mammalia from such reptilian ancestors. The fact of the matter is, of course, that far more complete knowledge than is at present availablenot merely of the skull but of the whole skeletonwould be necessary to identify the ancestor of the Mammalia, and even should this ancestor be in the distant future identified, it will still be impossible in the absence of information as to its organs other than the skeleton-such as, for example, its heart and main blood-vessels and its reproductive arrangements-whether it can safely be regarded as falling within the boundary of the group Reptilia.

Another shortcoming which frequently invalidates the conclusions of the less thoughtful palæontologists is the failure to appreciate physiological considerations. Striking examples are seen in speculations on the phylogeny of cephalopods based entirely on shell structure and ignoring the immensely important flotation effects of the gas in the chambers of the shell.

Equally striking are the efforts still made to bolster up the Balfour theory that the pectoral and pelvic limbs of the vertebrates are persisting and enlarged portions of a once continuous structure along the side of the body. Long ago it was shown that the embryological foundation of this theory was unsound. Later on, it was shown to be not merely unsound but also erroneous. But still it survives, its supporters unmoved by the physiological considerations which make it entirely improbable. One fact alone, that in every vertebrate the muscular system is in its early stage composed of segmentally arranged myotomes, indicates clearly that the primitive mode of movement of the vertebrate was propulsion through a watery medium by waves of lateral flexure passing back from the head region, and a full appreciation of the perfection of this method of propulsion is sufficient to indicate that the evolution of a new type of motor organ in all probability had to do not with swimming but with making use of solid features in the environment to lever the body forwards. The detailed investigation of the external gills of Polypterus, Lepidosiren, Protopterus and urodele amphibians has disclosed the existence within the phylum Vertebrata of a type of organ which possesses the full potentiality of giving rise in the course of evolution to a purely motor organ or limb. Never. theless, we find many palæontologists still ignoring such considerations and quite unnecessarily making use of the Balfour theory to provide interpretation for fossil fragments such as those of the ancient shark Cladoselache.

Another old-fashioned idea which is allowed to persist in spite of its being untenable in the light of modern knowledge is that which derives the lung of land vertebrates from the air-bladder characteristic of teleostean fish. This no doubt seemed a natural enough idea to those whose freedom of vision was effectively blinkered by the general principle that land animals have evolved out of aquatic, and who did not pause to reflect that the teleostean fishes form the terminal twigs of a branch of the Vertebrata showing the highest degree of evolution for a free swimming existence and inseparably linked with this mode of existence.

What we now know, however, of the comparative anatomy and embryology of air-bladder and lung in the archaic vertebrates leaves no escape from the startling conclusion that the air-bladder of the teleostean fish, instead of representing a condition ancestral to that of the typical lung, is to be interpreted in exactly the opposite fashion. The evidence is, in fact, convincing that the airbladder of the teleost is the modified right lung of an air-breathing ancestor.

I should not conclude this article without again directing attention to the fact that one of these archaic vertebrates, namely, Lepidosiren, happens to possess a character in the relatively enormous size of its cellular and particularly nuclearstructures which renders it of unusual value for the study of 
histogenesis and especially gametogenesis. It was a delightful, though distracting, experience to observe for the first time the beautiful mitotic figures of Lepidosiren in those days when Cambridge teaching was still sceptical regarding the existence of centrosomes! The value of Lepidosiren material for the investigation of celldetail is well brought out by the beautiful studies on the histogenesis of the blood by Bryce, on microgametogenesis by Agar, and on neurone relations by Ballantyne. The last-mentioned provides a typical case of new facts which, if they are really facts-and that they are facts, accurately described, I can personally testify-are shattering to one of the most sacred beliefs, for neurofibrils can be clearly seen to pass across the synaptic junction and plunge down into the cell-body of the next neurone.

Various ideas of a more general kind bearing on the principles of evolutionary theory have been inspired by these researches: that variability is to be regarded not as a phenomenon by itself but merely as one aspect of the general instability inherent in all living substance ; that the selection of variations in a definite direction necessarily involves the selection of the tendency to vary in that particular direction, and therefore necessarily results in 'orthogenesis'; that the phenomenon of parasyndesis discloses the existence of an attractive force which draws like chromatin together, and that this, while explaining the clumping together of like chromatin at successive points in the chromosome, renders unnecessary the assumption that the material basis of heredity consists of discrete and separate units or 'genes'.

Finally, I would urge, my prolonged experience in research has served to emphasize a consideration that is too often ignored, namely, that it is not sufficient to be content with making use of newly determined facts simply as arguments for or against already existing theories. On the contrary, it is essential that from time to time there should be a stock-taking, in which the body of relevant facts as now known is examined from a detached point of view, and the endeavour made by judicial consideration to arrive at a sound conclusion as to what general formula adequately fits the knowledge of to-day.

\section{Food Storage and Research}

$\mathrm{T}$ HE report of the Food Investigation Board describes the general activities of the Board and, in summary form, the scientific researches carried out by the members of the food investigation staff, under the general direction of $\mathrm{Mr}$. E. Barnard, the director of food investigation.* References are given to published work, but the special purpose of the report is to record the latest progress in those investigations which have not yet reached the stage at which full publication of the results is feasible.

Sir Joseph Barcroft was appointed chairman, on the resignation of Sir Frank Smith. Mr. Blackman, Prof. Hilditch and Sir Thomas Middleton were re-appointed members of the Board. Two special reports have been published, the first by $\mathbf{R}$. B. Haines, summarizing the more important data relating to the invasion of animal tissues by micro-organisms and their control (Special Report No. 45), and the second by C. H. Lea on rancidity in edible fats (Special Report No. 46).

Members of the food investigation staff paid visits to South Africa, Germany and the United States and Canada during the year. Broadly speaking, the impression which the Board has gained from the report on the American tour is

- Report of the Food Investigation Board for the year 1937. (Department of Scientific and Industrial Research.) Pp. 266+v. (London: H.M. Stationery Office, 1938.) 48. net. that while Great Britain is in no way behindhand in research on the handling and storage of foodstuffs, the application of science in this field is not so forward here as in the United States. There, the active belief of the leading industrialists in the value of research, and their keenness to apply scientific method and knowledge in the food industry were striking; and so was their readiness to spend large sums in developing new processes and in introducing new products to the public.

Reference is made in the report to the recommendation of the committee appointed to review the scope and form of the "Index to the Literature of Food Investigation", that this publication should be continued. The Board endorsed this recommendation and decided that the "Index" should cover the whole of the field which lies between the production of foodstuffs on one hand, and nutrition on the other hand; that it should be brought up to date as quickly as possible and should be published quarterly instead of halfyearly. In pursuance of this decision, the "Index" to the literature published in 1937 has now been issued, as vol. 9, Nos. 1-4. It is hoped to complete shortly vol. 7, No. 2 and vol. 8, which will deal with the literature published during 1935 and 1936.

From time to time, the Board is asked whether food that has been stored by modern methods, 